\title{
Prophylactic, Suppressive and Curative Potentials of a Polyherbal Antimalaria Mixture in Plasmodium Berghei Infected Mice
}

\author{
Suleiman Mikailu ${ }^{1 *}$, Vigara Sophia Ledumbari ${ }^{1}$, Nzereogu Chibuike Stephen $^{1}$, Doris Nnenna \\ Ajibo $^{2}$, Afieroho Ozadheoghene Eriarie ${ }^{1}$, Kio Anthony Abo ${ }^{1}$ \\ ${ }^{1}$ Department of Pharmacognosy and Phytotherapy, Faculty of Pharmaceutical Sciences, University of Port \\ Harcourt, Nigeria \\ ${ }^{2}$ Department of Pharmacology and Experimental Toxicology, Faculty of Pharmaceutical Sciences, University of
} Port Harcourt, Nigeria

*Corresponding Author: Suleiman Mikailu, Department of Pharmacognosy and Phytotherapy, Faculty of Pharmaceutical Sciences, University of Port Harcourt, Nigeria

\begin{abstract}
:
Objective

There is an increasing interest in the development of combination therapies used in the treatment of malaria and other ailments in folk medicine. This study evaluates the anti-malarial potential and constituents of a Polyherbal extract used in the western part of Nigeria in treating malaria.

\section{Materials and methods}

Polyherbal extract (PE) was prepared from a decoction of the dried leaves of Morinda lucida (ML) and Azadiracta indica (AI) and stem barks of Alstonia boonei (AB), Harungana madagascariensis (HM) and Enatia chlorantha (EC) in ratio 1.0:0.5:1.5:1.0:1.5 respectively. Acute toxicity and anti-malarial assay were evaluated in vivo at different doses of 200, 400 and $800 \mathrm{mg} / \mathrm{kg}$ with Chloroquine and distilled water as controls using Chloroquine sensitive Plasmodium berghei infected mice. Phytochemical constituents, thin layer chromatographic conditions and Fourier Transform Infrared Spectroscopy (FTIR) spectrum of the polyherbal were assessed.
\end{abstract}

\section{Results}

Safety of the PE at 5000mg/kg was recorded. Prophylactic activity of the extract exhibited significant ( $p>0.05)$ low percentage parasitaemia $(0.55 \%)$ at $800 \mathrm{mg} / \mathrm{kg}$ compared to chloroquine (1.56\%). Chemosupspressive was significantly effective at a lower dose $(200 \mathrm{mg} / \mathrm{kg})$ in comparison with negative control. The extract exhibited insignificant curative effect in the plasmodium infected mice. Alkaloids, saponins, triterpenoids, flavonoids, cardiac glycosides were found to be present in the extract. FTIR spectrum showed the fingerprint identity of the extract.

\section{Conclusion}

These findings could therefore substantiate the use of the herbal mixture in folk medicine for preventing and treating malaria infection.

Keywords: Anti-malaria, Harungana madagascariensis, Ethnomedicine, Fingerprint

\section{INTRODUCTION}

Malaria is one of the most prevalent and debilitating diseases afflicting humans. It is regarded as a tropical disease. Malaria is a life-threatening disease caused by parasites that are transmitted to people through the bites of infected female anopheles mosquitoes ${ }^{[1]}$. Plasmodia parasites have complex life cycles involving vertebrate and insect hosts. Five species of Plasmodium are known to infect humans and these include $P$. Ovale, . vivax, P.malariae, P. knowlesi, P. falciparum. In 2017, there were an estimated 219 million cases of malaria in 87 countries. The estimated number of malaria deaths stood at 435,000 in 2017. The WHO African Region carries a disproportionately high share of the global malaria burden. In 2017, P. falciparum accounted for $99.7 \%$ of estimated malaria cases in the WHO African Region, as well as in the majority of cases in the WHO regions of South-East Asia (62.8\%), the Eastern Mediterranean (69\%) and the Western Pacific (71.9\%). The diagnosis of malaria usually 
consists of microscopic examination of the parasites in stained thick and thin blood smears of peripheral blood. Malaria is managed by targeting the parasite in one or more of the stages of the life cycle prominently during the schizogonic phase to give rise to either clinical cure or radical cure. In clinical cure, the blood schizonts and/or the tissue schizonts are partly eliminated bringing about the elimination of the malaria symptoms because the parasite population left will not be enough to give rise to malaria symptoms. In radical cure, the entire Plasmodium population is eliminated including the hypnozoites that occur with the $P$. vivax and $P$. malariae. This is done with tissue hypnozonticites such as primaquine ${ }^{[2]}$. However, the emergence of resistance in the treatment and advent of artemisinin combination therapy has given credence to investigating plant mixtures and decoctions from ethnomedicine. A wide variety of plants belonging to several families have been previously identified through ethnobotanical and ethnopharmacological studies as anti-malarial medicinal plants [3]. Plant combination therapy has been the model of treatment in most African traditional medicine.

Alstonia boonei De wild belong to the family Apocynaceae. It is also known as "God's tree" in West African origin. It's a tall forest tree that can reach $45 \mathrm{~min}$ height and $3 \mathrm{~m}$ in girth, with leaves oblanceolate in shape, and airborne whorls at the end. The flowers are yellowish-white and fruits pendulous paired, with follicles up to $16 \mathrm{~cm}$ long containing seeds. It is used in the management of painful menstruations, painful urethritis in men and diabetes. The latex of the bark is applied to snakebite and swellings caused by filarial infections ${ }^{[4]}$. Pharmacological activities including Antimalaria, antifertility, anti-inflammatory, antibacterial, antiplasmodial, antidiabetic, antidiarrhoea and antipsychotic of $A$. boonei has previously been reported ${ }^{[5]}$. Azadirachta indica A. Juss. belongs to the family Meliaceae and commonly known as "Neem tree"e in English is a perennial tree that can reach a height of 15-20 metres (49-66 ft), and rarely 35-40 metres (115-131 ft). Its medicinal use includes its use in poultry, as the bark is used to treat wounds, diarrhoea, ticks and lice. They are also used in skin disorders including ringworm, alopecia, eczema, urticarial, scabies, ticks and lice. Other minor indications include metritis, orchitis and tetanus, rinderpest, rheumatism, stoppage of urination, swelling of the kidney, mastitis, otitis and abscess in the ear in veterinary use ${ }^{[6]}$. Neem has been implicated for having anti-malarial, hepatoprotective, antimicrobial, anti-malarial, antidiabetic, anticancer and wound healing activity ${ }^{[7]}$. Morinda lucida known as Oruwo in the Southwestern part of Nigeria is a medium-sized tree at maturity. Stem bark infusion is used as an anti-malarial and antidiabetic ${ }^{[8]}$. Anti-malarial, antimicrobial, gastroprotective, antioxidant, antiviral, antidiabetic, antiinflammatory, anticonvulsant and analgesic and pyretic activity of Morinda lucida extracts have all been reported ${ }^{[9]}$. Harungana madagascariensis belongs to the family Hypericaceae and is native to tropical Africa. It has been reported to have antioxidant, antimicrobial, antiprotozoal, antisickling, anti-inflammatory and antioxidant ${ }^{[10]}$. Enantia chlorantha is an ornamental tree that belongs to the family annonaceae. It may grow up to $30 \mathrm{~m}$ high with dense foliage and a spreading crown. It has also been reported to have gastroprotective, hepatoprotective, antiviral, anticonvulsant, antiinflammatory, fertility booster and anti-malarial activity ${ }^{[11]}$. The present study was aimed at evaluating the combined effect of the five agents of malaria in plasmodium infected mice.

\section{Materials AND Methods}

\subsection{Plant Collection}

The stem bark of $\mathrm{HM}, \mathrm{AB}$ and the leaves of $\mathrm{AI}$ used for this investigation were collected from the botanical garden of the Faculty of Pharmaceutical Sciences, University of Port-Harcourt, Rivers state while ML leaves were collected from Rumualogu, Rivers State. EC was purchased from mile 3 market, Rivers State. The plants were further identified and authenticated in the Herbarium of the Department of Pharmacognosy and Phytotherapy, Faculty of Pharmaceutical Sciences, University of Port Harcourt. Voucher numbers were obtained for the plants viz: UPHH462, UPHA466, UPHM463, UPHR464, UPHA465 respectively.

\subsection{Preparation of the $P E$}

The dried and powdered leaves of $\mathrm{AI}$ and ML and the dried and powdered stem barks of AB, HM, and EC were mixed in the ratio 0.5:1.0:1.5:1.0:1.5 respectively to obtain a total of $386.5 \mathrm{~g}$ of Combined powdered plant material. The mixed plant materials were boiled with $2 \mathrm{~L}$ of distilled water at $100^{\circ} \mathrm{C}$ for one hour, allowed to cool and then filtered. The marc was re-extracted in the same manner twice. The extract was combined and evaporated to dryness on a water bath. 


\subsection{Experimental Mice}

Both male and female mice Mus musculus (Muridae), 4-6 weeks of age, weighing between 19g and $31 \mathrm{~g}$ were used for all experiments. The mice were obtained from the animal house of the Department of Pharmacology and Toxicology of the Faculty of Pharmaceutical Sciences, University of Port Harcourt. They were kept at $25 \pm 2{ }^{\circ} \mathrm{C}$ with a $12 \mathrm{~h}$ photoperiod per day and provided with standard feed and water ad libitum.

\subsection{Acute Toxicity Studies $\left(\mathbf{L D}_{50}\right)$}

The aqueous plant extract was given to animals which were divided into six groups of three animals each, according to their body weights $(150-160 \mathrm{~g})$. The acute toxicity study was carried out on experimental healthy albino rats using Lorke's method ${ }^{[12]}$. In the first phase of the study, nine mice were randomized into three groups of three mice each and were given 10,100 , and $1000 \mathrm{mg} / \mathrm{kg}$ body weight of the PE orally. They were observed for 24 hours for death and any sign of toxicity. In the second phase of the study,

another fresh set of nine albino rats were randomized into three groups of three mice each and were given 1600, 2900 and 5000mg/kg body weight of the PE. They were observed for 24 hours for signs of toxicity. The oral median lethal dose was calculated using the formula:

$\mathrm{LD} 50=\sqrt{ }($ Minimum toxic dose $\times$ maximum tolerated dose $)$.

\subsection{Plasmodium Berghei}

Chloroquine-sensitive Plasmodium berghei strain was used for the induction of malaria in the experimental mice. The parasite was obtained from the Malaria Research and Reference Reagent Resource Center (M-RAB) of the University of Port-Harcourt. Three mice infected with Plasmodium berghei were used as the donor source. The parasitaemia levels of the three mice were determined after which equal quantities of blood were obtained from the tails of the respective mice and diluted with $0.9 \%$ normal saline solution as the stock and used to infect both the suppressive and prophylactic test mice by injecting $0.5 \mathrm{ml}$ of the diluted blood via intraperitoneal injection to each of the mice.

\subsection{Evaluation of the Prophylactic Anti-Malarial Activity of the PE}

The chemoprophylactic activity of the PE was performed using a modified method described by Voravuth et al., (2018) ${ }^{[13]}$. There were five groups of $P$. berghei NK 65 infected mice in which each group contains six mice. The mice in groups 1,2 and 3 were administered 200, 400 and $800 \mathrm{mg} / \mathrm{kg}$ of the PE orally respectively. The mice in group 4 were administered $10 \mathrm{mg} / \mathrm{kg}$ of chloroquine orally. The mice in group 5 were administered $0.2 \mathrm{ml}$ of distilled water and the dosage administration continued once daily for the next three days respectively. At 24 hours after dosage administration, the mice were inoculated with $32.3 \%$ parasitized erythrocytes by intraperitoneal injection. At 72 hours after the inoculation of the mice with the $P$. berghei, both thick and thin smears of the blood of each of the mice in all the groups were obtained through the tail. The smears were fixed with ethanol and stained with Giemsa for microscopic identification and quantification of parasitized and total red blood cells.

\subsection{Evaluation of the Suppressive Anti-Malarial Activity of the PE}

Evaluation of the chemo-suppressive anti-malarial activity of the polyherbal using a modified standard four-day Suppressive test ${ }^{[13]}$ involves five groups of mice in which each group contains six mice each. Each of the groups was inoculated with $32.3 \%$ parasitized erythrocytes by intraperitoneal injection. Three hours after inoculation, the mice in groups 1,2 and 3 were administered $200 \mathrm{mg} / \mathrm{kg}$, $400 \mathrm{mg} / \mathrm{kg}$ and $800 \mathrm{mg} / \mathrm{kg}$ of the PE respectively, the mice in group 4 were administered $10 \mathrm{mg} / \mathrm{kg}$ of chloroquine orally and the mice in group 5 were administered $0.2 \mathrm{ml}$ of distilled water and the dosage administration continued once daily for the next three days respectively. At 24 hours after day 3 of the dosage administration, both thick and thin smears of the blood of each of the mice in all the groups were obtained through the tail and prepared as stated in prophylactic evaluation.

\subsection{Evaluation of the Curative Anti-Malarial Activity of the PE}

The curative potential of the polyherbal was evaluated as described by Ryley and Peters (1970) ${ }^{[14]}$. After three days post-induction of the $P$. berghei NK 65 parasite, the mice were grouped in four different cages containing six mice each. Group 1, 2, and 3 received 200, 400 and $600 \mathrm{mg} / \mathrm{kg}$ of the PE respectively. The mice in group 4 were administered $10 \mathrm{mg} / \mathrm{kg}$ of chloroquine. Mice in group 5 were 
not inoculated but administered $0.2 \mathrm{ml}$ of distilled water and the dosage administration continued once daily for the next seven days respectively. Thin blood smears were obtained and prepared as stated in the chemo-suppressive test on days $0,3,7$ and 14 to monitor the level of parasitaemia by microscopic assessment of parasitized and total red blood cells.

\subsection{Determination of Percentage Survival}

Mortality was monitored daily throughout the study, from the time of infection up to the end of the $7^{\text {th }}$ day in all the groups. The percentage of survival time was calculated for each group by using the formula:

$$
\% \text { survival }=\frac{\text { number of animals }(\text { Day } 0)-\text { number of animals (Day } 7)}{\text { Number of animals (Day } 0)} \times 100
$$

\subsection{Phytochemical Screening}

Phytochemical screening was carried out on the PE to detect the presence of secondary metabolites using described standard methods ${ }^{[15,16]}$.

\subsection{Thin-Layer Chromatography (TLC)}

The PE was predisposed to chromatographic profiling using TLC based method. A pre-coated silica gel $\mathrm{GF}_{254}$ plate of $10 \times 4 \mathrm{~cm}$ marked $1 \mathrm{~cm}$ away from both ends. Glass capillary tubes were used to spot on the plate and developments were done using varied ratios of mobile phases containing butanol, acetic acid, water. The plates were visualized in both daylight and ultraviolet light (UV). The chromatograms were detected with $60 \%$ sulphuric acid spray in which the plate was activated at $100^{\circ} \mathrm{C}^{[17]}$.

\subsection{Fourier Transform Infrared Spectroscopy (FTIR) Assay}

Buck scientific M530 USA FTIR was used for the analysis. This instrument was equipped with a detector of deuterated triglycine sulphate and beam splitter of potassium bromide. The software of the Gram A1 was used to obtain the spectra and to manipulate them. An approximately $1.0 \mathrm{~g}$ of sample was properly placed on the salt pellet. During measurement, FTIR spectrum was obtained at frequency regions of 4,000-600 cm-1 and co-added at 32 scans in $4 \mathrm{~cm}-1$ resolution. FTIR spectra were displayed as transmitter values.

\subsection{Data and Statistical Analysis}

The average parasitaemia was determined by obtaining the percentage of the ratio of parasitized to the total number of RBC. The average percentage of chemo-suppression (or parasite clearance) was calculated as $100 \times[(\mathrm{A}-\mathrm{B}) / \mathrm{A}]$, where $\mathrm{A}$ is the average parasitaemia of the negative control group and $\mathrm{B}$ is the average parasitaemia of the test group. The effective doses $\left(\mathrm{ED}_{50}\right)$ were determined online (www.aatbio.com) while the one-way analysis of variance between groups and negative control was done with GraphPad Prism 9.0.2 . A P value of $<0.05$ was considered statistically significant.

\section{Results}

\subsection{Percentage Yield}

The air-dried and powdered stem bark of $A B(200 \mathrm{~g}), H M$ was $(135 \mathrm{~g}), E C(200 \mathrm{~g})$ and leaves of $M L$ $(135 \mathrm{~g})$ and $A I(67 \mathrm{~g})$ and were combined. The $737 \mathrm{~g}$ of the powdered plant materials yielded $150 \mathrm{~g}$ after decoction with a percentage yield of $20.32 \%$.

\subsection{Acute Toxicity}

The animals survived the doses of the PE given to them at a single dose at different phases of the study. Signs of toxicity were not exhibited by the animals. The $\mathrm{LD}_{50}$ was therefore estimated to be $5000 \mathrm{mg} / \mathrm{kg}$.

\subsection{Effect of PE on Prophylactic Evaluation}

In Table 1, the treatments showed significant ( $p>0.05)$ percentage reduction of parasitaemia level in the $P$. berghei infected mice in a dose-dependent manner when compared to distilled water, control 
Prophylactic, Suppressive and Curative Potentials of a Polyherbal Antimalaria Mixture in Plasmodium Berghei Infected Mice

groups Consequently all the treatments have a lower percentage of parasitaemia than the chloroquine treated group.

Table1. Effect of PE on percentage parasitaemia level in P. berghei-infected mice in the prophylactic evaluation

\begin{tabular}{|l|l|l|}
\hline Treatment & $\begin{array}{l}\text { Mean parasitaemia level } \\
\text { =Standard deviation }\end{array}$ & ED $_{\mathbf{5 0}}$ \\
\hline PE $200 \mathrm{mg} / \mathrm{kg}$ & $1.17 \pm 0.1528 \%^{*}$ & 456.7 \\
\hline PE $400 \mathrm{mg} / \mathrm{kg}$ & $1.04 \pm 0.4928 \%^{*}$ & \\
\hline PE $800 \mathrm{mg} / \mathrm{kg}$ & $0.55 \pm 0.5119 \%^{*}$ & \\
\hline Chloroquine $10 \mathrm{mg} / \mathrm{kg}$ & $1.56 \pm 0.2182 \%^{*}$ & \\
\hline Distilled water & $2.22 \pm 0.4481 \%$ & \\
\hline
\end{tabular}

Values represent Mean \pm Standard Deviation of 6 mice, PE: PE, ED 50 : Median Effective dose, *Significantly different $(p>0.05)$ when compared to the negative control.

Table2. Percentage survival of infected treated mice after 14 days

\begin{tabular}{|l|l|l|l|}
\hline Days & PE200 & PE400 & PE800 \\
\hline Number of nice at Day 0 & $6 / 6$ & $6 / 6$ & $6 / 6$ \\
\hline Number of mice at Day 14 & $6 / 6$ & $5 / 6$ & $5 / 6$ \\
\hline Percentage survival & $100 \%$ & $83.3 \%$ & $63.3 \%$ \\
\hline
\end{tabular}

The numerator represents the number of mice that are active while the denominator represents the total number of mice.

\subsection{Effect of PE on Chemo-Suppressive Evaluation}

It was observed that the group treated with 200 and $400 \mathrm{mg} / \mathrm{kg}$ showed a significant ( $p>0.05)$ decrease in percentage parasitaemia when compared to the negative control (distil water) in Fig 1. Only the $200 \mathrm{mg} / \mathrm{kg}$ treatment group showed a significant percentage of parasitaemia when compared with the positive control (chloroquine $10 \mathrm{mg} / \mathrm{kg}$ )

\section{Fig 1. Suppressive effect of the Polyherbal on the mice}

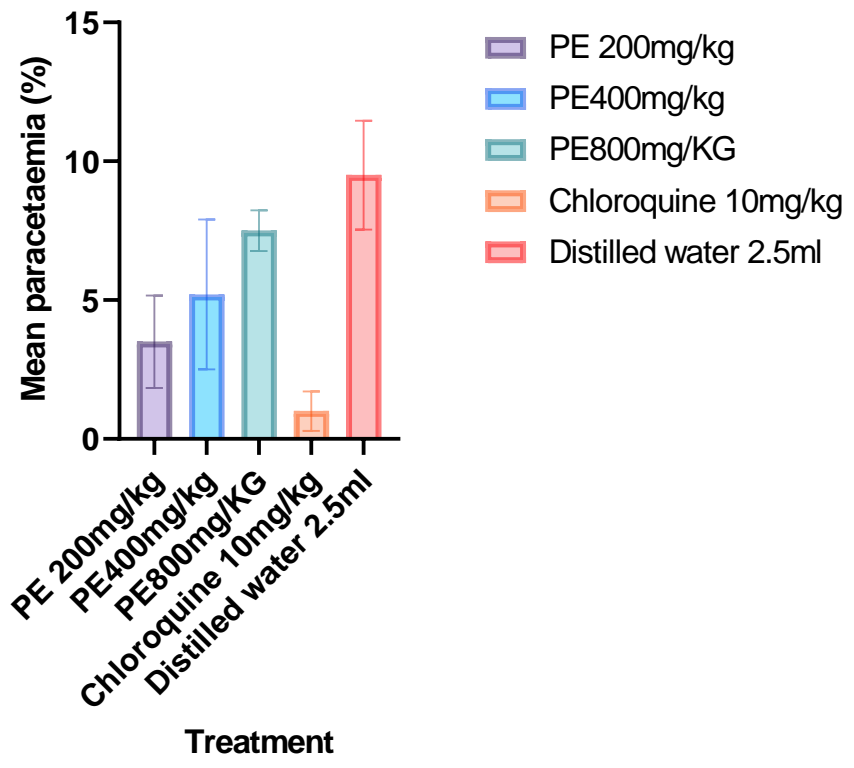

Values represent Mean \pm Standard Deviation of 6 mice, PE: PE

\subsection{Effect of PE on Curative Evaluation}

None of the concentrations of the extract in fig. 2 exhibited a reduction in parasitaemia level of the $P$. berghei infected mice. The percentage parasitaemia in the extract treatment groups was similar to the negative control while chloroquine exhibited $100 \%$ clearance of the parasitaemia. 


\section{Fig 2. Curative effect of the Polyherbal on the mice}

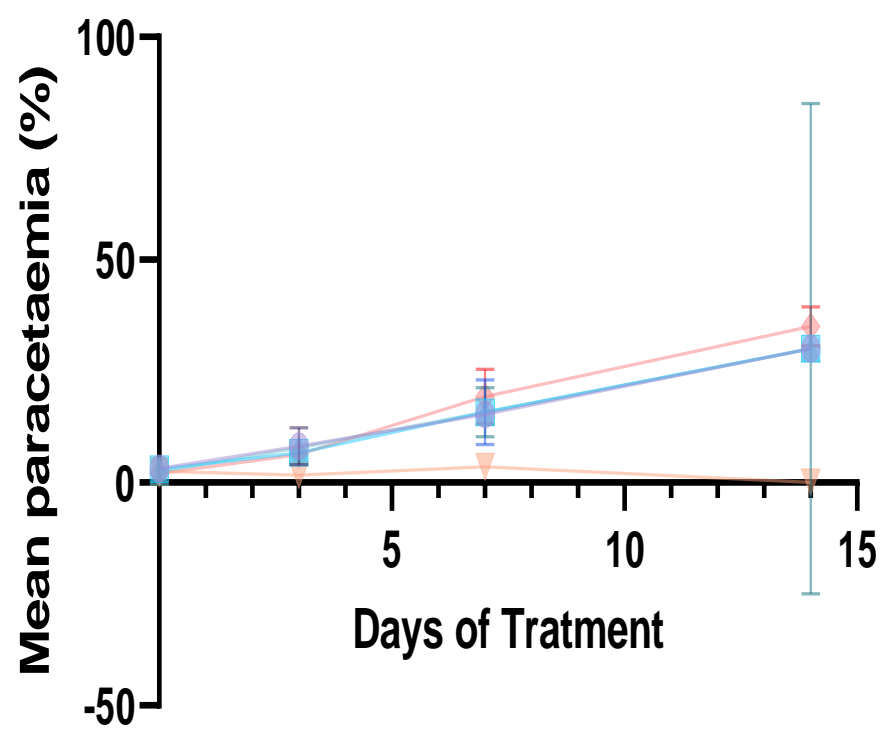

PE 200mg/kg

PE 400mg/kg

PE $800 \mathrm{mg} / \mathrm{kg}$

Chloroquine $10 \mathrm{mg} / \mathrm{kg}$

Distilled water $2.5 \mathrm{ml}$

Values represent Mean \pm Standard Deviation of 6 mice, PE: PE

\subsection{Percentage Survival after 14 Days}

Mortality was monitored from the time of infection to the end of the $14^{\text {th }}$ day in all the treatment groups in the curative evaluation. In the group treated with chloroquine $(10 \mathrm{mg} / \mathrm{kg})$ and $200 \mathrm{mg} / \mathrm{kg}$ of the polyherbal, the percentage survival was $100 \%$. In 400 and $800 \mathrm{mg} / \mathrm{kg}$ treated groups, the percentage survival was 83.3 and $66.7 \%$ respectively.

\subsection{Phyto-Constituents of the PE}

The phyto-constituents detected in the PE were alkaloid, saponins, tannins, flavonoids, cardiac glycosides, triterpenoids and carbohydrates as presented in Table 3. Anthraquinone was not detected.

Table3. Phytochemicals of the Ployherbal extract

\begin{tabular}{|l|l|}
\hline Phytochemicals & Remark \\
\hline Alkaloids & + \\
\hline Anthraquinones & - \\
\hline Flavonoids & + \\
\hline Saponins & + \\
\hline Tannins & + \\
\hline Triterpenoids & + \\
\hline Cardenolides & + \\
\hline Carbohydrates & + \\
\hline
\end{tabular}

+: Present, -: Absent

\subsection{Chromatographic Identification of the PE}

The PE showed a better separation of its characteristic constituents on a thin layer chromatography on a pre-coated Silica Gel $\mathrm{GF}_{254}$,in a mobile phase of butanol: acetic acid: water (4:1:5) and visualized at $365 \mathrm{~nm}$. Notable Rf were $0.73,0.63,0.53$, and 0.33 with characteristic light blue, brown, yellow and brown colours respectively.

\subsection{FTIR Spectrum of the PE}

The fingerprint obtained from the infrared spectrum the PE in Fig 3 was to specifically identify the quality of the PE. The fingerprint region showed a unique pattern that describes the PE. The frequency region also showed the presence of $\mathrm{OH}$ (3287-3438) stretching, alkyl group, $\mathrm{CH} 2$ and $\mathrm{CH} 3$ frequencies at 2133, 2902, and 2973 respectively. 


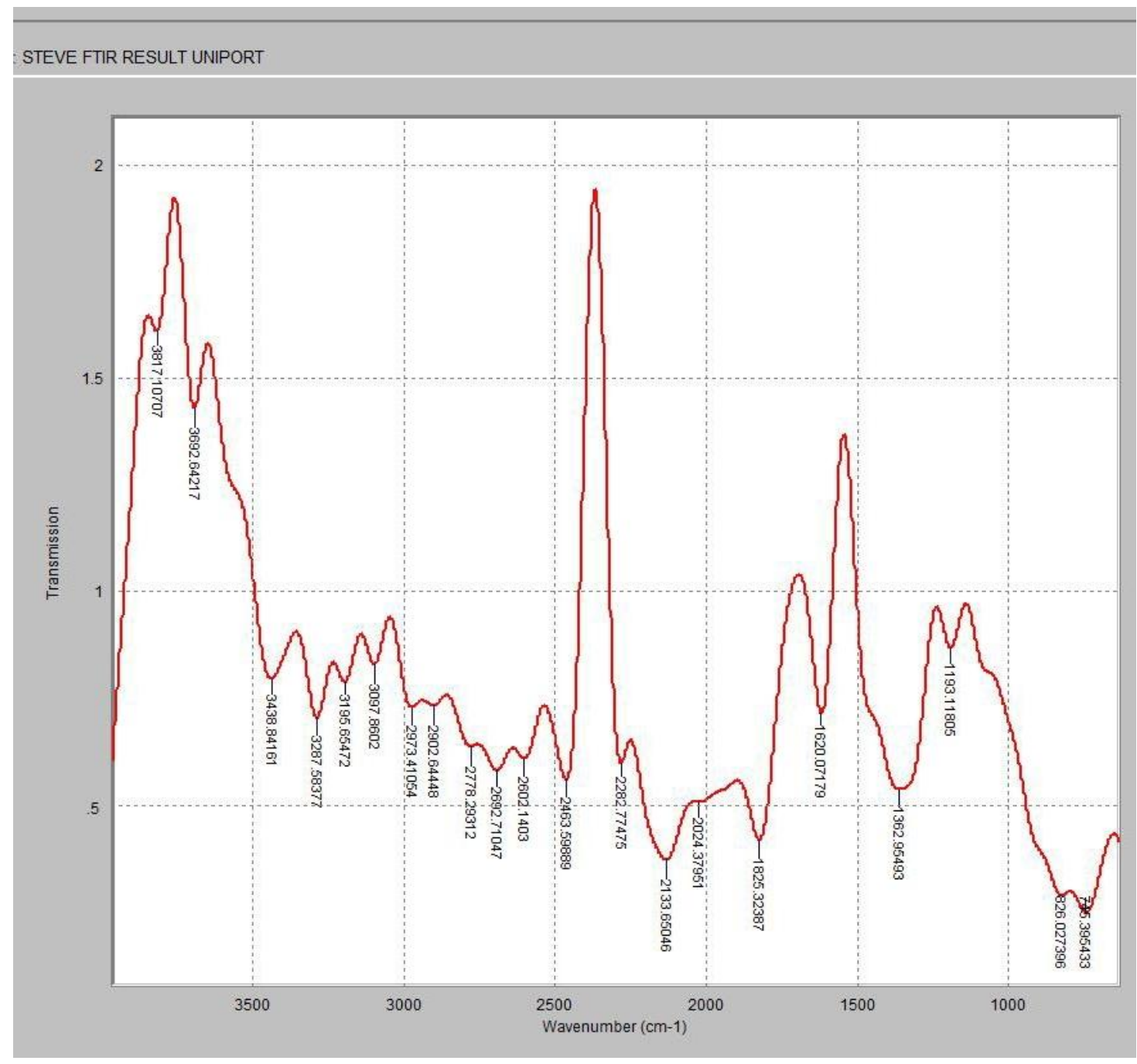

Fig3. FTIR spectrum of the PE

\section{DISCUSSION}

One major constraint of anti-malarial monotherapy is the growth of resistance by the malarial parasites ${ }^{[18,19]}$. With the discovery of artemisinin from Artemisia annua and the adoption of artemisinin combination therapy (ACT) as the current anti-malarial treatment policy, it is logical that anti-malarial plant drug discovery efforts be tilted towards exploring decoctions of medicinal plant materials used for anti-malarial in traditional medicine ${ }^{[20]}$. Decoctions in herbal medicine are multicomponent and could therefore be principally considered as 'natural' combination therapies ${ }^{[21]}$. Hence, resistance to the malarial parasite is not known in multicomponent herbal mixtures which often consist of two or more morphological parts of plant(s) to provide synergistic antiplasmodial actions or to perform other formulation roles as pharmaceutical excipients ${ }^{[22]}$.

Each of the plants in the mixture has earlier been reported to have anti-malarial potential: Alstonia boonei bark [23]; Azadirachta indica and Morinda lucida leaves [24]; Enantia chlorantha [25]; Harungana madagascariensis stem bark ${ }^{[26]}$

The primary aim of this study was to ascertain the efficacy and safety of the claimed use of the PE in treating malaria. In this study, acute behavioural signs of toxicity such as paw licking, salivation, stretching, and reduced activity, were observed at dose $5000 \mathrm{mg} / \mathrm{kg}$ however there was no mortality at all the dose levels. The oral median lethal dose $\left(\mathrm{LD}_{50}\right)$ was estimated to be $>5000 \mathrm{mg} / \mathrm{kg}$ body weight. This high safety profile may have been responsible for its widespread use in ethno-therapeutic interventions. Plasmodium berghei parasite is used in treatment outcomes of any suspected antimalarial agent due to its high sensitivity to Chloroquine making it the appropriate parasite for this study ${ }^{[27]}$. 
In the suppressive study, although $200 \mathrm{mg} / \mathrm{kg}$ and $400 \mathrm{mg} / \mathrm{kg}$ showed a significant decrease in parasitaemia level $(\mathrm{P}<0.05)$, the decrease in parasitaemia was regressing with an increase in the concentration of the PE. It was also observed that the mice in the groups of the higher doses were dying before the end of the experiment. This, therefore, suggests that an increase in the dose of the extract become toxic to the animals and does not hinder the progression of the parasitaemia level in the mice and thereby leading to the death of the animals in the group given the higher doses. It is as well suggests that lower doses below $200 \mathrm{mg} / \mathrm{kg}$ could be a better range to be administered to obtain a better anti-malarial suppressive effect as observed that the fixed smear of the blood of the animals treated with a lower concentration of the PE showed lesser bleaching of the red blood cells of the animals. With an increase in dose, it could as well be suggested that the active sites of the PE were being blocked which resulted in the diminishing anti-malarial suppressive effect with an increase in dose.

In the curative study where malaria has already been established in fig 3, the PE did not show a significant $(\mathrm{p}<0.05)$ decrease in parasitaemia level even at a dose of $800 \mathrm{mg} / \mathrm{kg}$ up to the fourteenth day. This, therefore, suggests that the PE has no curative effect on already established malaria infection. It was also observed that the group treated with a higher concentration of the extract had weight loss, shivering, and seizure which progressively led to the death of some of the animals before the end of the experiment. This could be as a result of a progression of the malaria infection and possible antagonistic effect of the scaffold constitutes of the Polyherbal.

In the prophylactic study, the polyherbal treated group exhibited a dose-dependent and significant decrease in $P$. berghei when compared with the untreated group. The study, therefore, indicated that the doses of $400 \mathrm{mg} / \mathrm{kg}$ and $800 \mathrm{mg} / \mathrm{kg}$ have a better prophylactic treatment effect of $P$. berghei $(\mathrm{P}<$ $0.05)$ than the standard chloroquine drug.

The absence of anthraquinones in the extract could suggest a possible reason for its ineffectiveness in early and established malaria infection stages since it was present in the individual plants that were claimed to have anti-malarial activity. The FTIR spectrum corroborated the phytochemical result with the absence of carbonyl functional group which could signal the presence of anthraquinone.

The thin layer chromatogram of the polyherbal which is also its identity showed the best separation in using a mobile phase of Methanol, Acetic Acid, Ethylacetate (5:0.5:4) and Butanol, Acetic Acid, Water $(4: 1: 5)$

In conclusion, the polyherbal was found to be safe at $5000 \mathrm{mg} / \mathrm{kg}$. It is effective in treating the early onset of malaria at low doses and prophylactic stage of $P$. berghei infection and ineffective in treating the early and established $P$. berghei infection which means that it should not be taken. The identity of the polyherbal is recorded for its thin layer chromatography and FTIR fingerprint spectrum.

\section{ACKNOWLEDGEMENT}

The authors are grateful to the staff of Centre for Malaria Research and Phytomedicine (CMRAP) of University of Port Harcourt for their support during the research.

\section{AUTHORS CONTRIBUTION}

Kio Anthony Abo conceived the experiment. Suleiman Mikailu and Afieroho Ozadheoghene Eriarie designed the experiment and wrote the manuscript. Vigara Sophia Ledumbari,Nzereogu Chibuike Stephen and Doris Nnenna Ajibo conducted the research.

\section{REFERENCES}

[1] WHO. 2017. 'Releases new guideline on insecticidal treated mosquito nets. http://www.who.int/mediacentre/news/releases/2007/pr43/en/. Accessed 2 November 2019.

[2] Ellis KP, Akoto YO, Matthew GA, Maxwell AB. 2019. Analysis of haematological parameters as predictors of malaria infection using a logistic regression model: A case study of a hospital in the Ashanti region of Ghana. Malaria Research and Treatment, 7:148-157.

[3] Titanji VP, Zofou D, Ngemenya MN. (2008). The anti-malarial potential of medicinal plants used for the treatment of malaria in Cameroonian folk medicine. Afr J Tradit Complement Altern Med. 10;5(3):302-21.

[4] Abbiw D. 1990. Useful Plants of Ghana: West African Uses of Wild and Cultivated Plants, Intermediate Technology Publications, Royal Botanical Garden, Kew, London,

[5] John PKA, Genevive EA, Boahen YO, Armah FO. 2012. A review of the ethnobotany and pharmacological importance of Alstonia boonei De Wild. (Apocynacea). ISRN Pharmacology, 10:540-587. 
[6] Ogbuewu P, Odoemenam VU, Obikaonu HO, Opara MN, Emenalom OO, Uchegbu MC. 2011. The growing importance of neem (Azadirachta indica A. Juss) in agriculture, industry, medicine and environment: A Review. Res J Med Plant, 5: 230-245.

[7] Muhammed F, Selma B, EHahir AK. 2011. Antiplasmodial effect of Azadiracta indica in experimental cerebral malaria. Journal of Animal Science, 10(4):254-276.

[8] Burkill HM, Dalziel JM.1997. The Useful Plants of West Tropical Africa. Families M-R Volume 4 2nd Ed Royal Botanic Gardens Kew

[9] Adeleye OO, Ayeni OJ, Ajamu MA. 2018. Traditional and medicinal uses of Morinda lucida. Journal of Medicinal Plants Studies, 6(2): 249-254

[10] Gervais M HB, Gesquiere LMT, Bel YMG, Hidayat H, Ivan RG, Bonaventure TN, Simeon FK. 2020. Phytochemistry and pharmacology of Harungana madagascariensis: mini Review Phytochemistry Letters, 35: $103-112$

[11] Tene TO, Ngouafong TF, Seukep AJ. 2016. Traditional uses, phytochemical and pharmacological profiles, and toxicity of Enantia chlorantha (Oliver): An overview. Edorium J Med, 3:12-18.

[12] Lorke D. 1983. A new approach to practical acute toxicity testing. Archive of Toxicology 54: 275-287.

[13] Voravuth S, Awatsada D, Pinanong O. 2018. Anti-malarial activity of kaempferol and its combination with chloroquine in Plasmodium berghei infection in mice. Hindawi Journal of Pathogens, 1-7

[14] Ryley JF, Peters W. 1970. The anti-malarial activity of some quinolone esters. Am J Trop Med Parasitol, 84:209-211

[15] Sofowora A. 1993. Medicinal plants and traditional medicine in Africa. 3rd Edition, pp 134-156.

[16] Harbone JB. 1998. Phytochemical methods. Chapman and Hall London. 3rd Edition pg 61

[17] Suleiman M, Ugwu CC, Adhekegba E, Afieroho OE, Abo KA. 2020 Anti-malarial potential of herbal combination containing Harungana madagascariensis, Costus afer and Citrus aurantifolia. International Journal of Research in Pharmacy and Pharmaceutical Sciences, 5(2): 25-30

[18] Nosten F, Van VM, Price R, Luxemburger C, Thway KL, Brockman A, McGready R, ter Kuile F, Looareesuwan S, White NJ. 2000. Effects of artesunate-mefloquine combination on incidence of Plasmodium falciparum malaria and mefloquine resistance in western Thailand: a prospective study. Lancet. 356:297-302

[19] White NJ. 2004. Anti-malarial drug resistance. J Clin Invest, 113:1084-92

[20] WHO.1993. WHO guidelines for the assessment of herbal medicines. Herbal Grom, 28:13-14

[21] Eberle J. 1834. A Treatise of Materia Medica and Therapeutics Volume 1. T. K. Collins and Co Printers, Philadelphia, p 258

[22] Majekodunmi SO, Adegoke OA, Odeku OA. 2008. Formulation of the extracts of Alstonia boonei as tablet dosage form. Trop J Pharm Res, 7:987-994

[23] Iyiola OA, Tijani AY, Lateef AM. 2011. Anti-malarial activity of ethanolic stem bark extract of Alstonia boonei in mice. Asian J Biol Sci, 4(3):235-243.

[24] Adepiti AO, Elujoba AA, Bolaji OO. 2014. In vivo anti-malarial evaluation of MAMA decoction on Plasmodium berghei in mice. Parasitol Res, 113:505-511

[25] Agbaje EO, Elueze NR. 2006. Anti-malaria activities of Enantia Chlorantha and Rauwalfia vomitora extracts in rodents malaria. Tropical Journal of Medical Research, 10(1): 11-14

[26] Iwalewa EO, Omisore NO, Adewunmi CO, Gbolade AA, Ademowo OG, Nneji C, Agboola OI, Daniyan OM. 2008. Anti-protozoan activities of Harungana madagascariensis stem bark extract on trichomonads and malaria. J. Ethnopharmacol. 117, 507-511.

[27] Peter IT, Anatoli VK. 1998. The current global malarial situation: Malaria parasite biology, pathogenesis and protection. ASM Press W. D. C, London, Pp. 11 - 22.

Citation: Suleiman Mikailu, et.al., (2021). "Prophylactic, Suppressive and Curative Potentials of a Polyherbal Antimalaria Mixture in Plasmodium Berghei Infected Mice". International Journal of Medicinal Plants and Natural Products (IJMPNP), 7(2), pp.1-9. https://doi.org/ 10.20431 /2454-7999.0702001

Copyright: (C) 2021 Authors. This is an open-access article distributed under the terms of the Creative Commons Attribution License, which permits unrestricted use, distribution, and reproduction in any medium, provided the original author and source are credited. 